\title{
Impermeable membranes for slab-track settlement mitigation
}

1 Joaquín Pérez-Romero PhD, MSc, DIC, CICCP Part-time Assistant Professor, Department of Art and Architecture, University of Málaga, Málaga, Spain (corresponding author: joaquin.perez@uma.es)

2 Matteo O. Ciantia PhD

Junior Research Fellow, Geotechnics Section, Department of Civil and Environmental Engineering, Imperial College London, London, UK
3 Marcos Arroyo PhD

Associate Professor, Geosciences Division, Department of Civil and Environmental Engineering, Polytechnic University of Catalonia, Barcelona, Spain

4 Jean Vaunat $\mathrm{PhD}$

Associate Professor, Geosciences Division, Department of Civil and Environmental Engineering, Polytechnic University of Catalonia, Barcelona, Spain
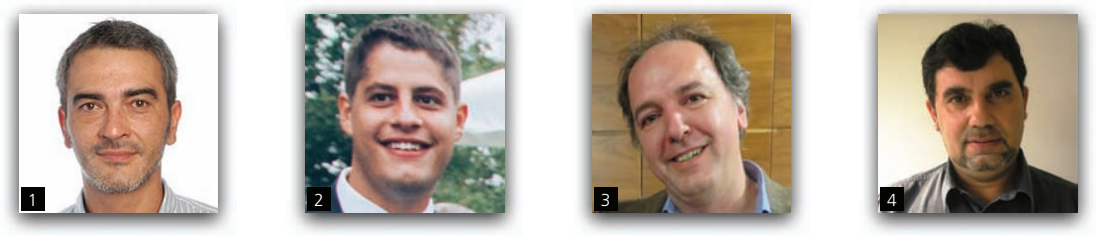

A series of numerical simulations is used to explore the effect of the geometrical disposition of-impermeable membranes in the overall performance of slab-track railway earthworks, with particular reference to the generation of settlement along several years of exposure to the atmosphere and the admissibility of these post-construction deformations according to the available standards. A methodology suitable to account for the effects of rail traffic loading and environmental actions over its service life is presented. To emphasise the effect of the waterimpermeable membranes on the atmospheric-induced embankment irreversible deformations, both semi-arid and wet climate conditions were investigated, making use of real climate data for a period of 10 years. The numerical results show that the calculated settlement can be beyond the admissible values and that the use of impermeable membranes is an available alternative for its mitigation.

\section{Notation}

$A_{1} \quad$ albedo

$A\left(N, W_{\mathrm{c}}\right) \quad$ amplification factor that depends on traffic repetitions

E current Young's modulus

$E_{0} \quad$ initial Young's modulus

$e_{\mathrm{v}} \quad$ internal energy of vapour water

$e_{\mathrm{W}} \quad$ internal energy of liquid water

$F_{\mathrm{u}} \quad$ environmental adjustment factor

Q2 $g$ gravity

$H_{\mathrm{c}} \quad$ convective (latent) heat flux

$H_{\mathrm{r}} \quad$ relative humidity

$H_{\mathrm{s}} \quad$ sensible heat flux

$h^{i} \quad$ thickness of the sublayer

I identity tensor

$I_{\mathrm{n}} \quad$ cloud index

$j_{\mathrm{E}} \quad$ evaporation flux

$j_{\mathrm{e}} \quad$ total energy flux

$j_{\mathrm{g}}^{\mathrm{w}} \quad$ advective flux of vapour gas phase

$j_{\text {sr }} \quad$ surface run-off flux

$j_{\mathrm{w}} \quad$ water flux through boundary $k$

$k$

$M_{\mathrm{r}}$

$N$

$P$

$P$

$P$

$P_{\mathrm{g}}$

$P_{\text {ga }}$

$P_{1}$

$P_{\mathrm{r}}$

$R_{\text {a }}$

$R_{\mathrm{g}}$

$R_{\mathrm{n}}$

$R_{\mathrm{s}}$

$S_{\mathrm{e}}$

$S_{\mathrm{r}}$

$S_{\mathrm{r}, 0}$

$S_{\mathrm{r}, \max }$

$S_{\text {r,res }}$ intrinsic permeability: $\mathrm{m}^{2}$

input parameter

resilient modulus

number of traffic repetitions

pressure for a measured $T$

rainfall

rainfall flux

gas pressure

atmospheric gas pressure

liquid pressure in the ground

precipitation

long-wave atmospheric radiation absorbed by the ground

and the radiation emitted by the ground

solar radiation

direct solar short-wave radiation

water retention curve

current degree of saturation

initial degree of saturation

maximum saturation ratio

residual saturation ratio 


\begin{tabular}{|c|c|}
\hline$T$ & temperature \\
\hline$T_{\mathrm{a}}$ & atmospheric temperature \\
\hline$T_{\mathrm{s}}$ & soil temperature \\
\hline$t$ & time \\
\hline$v_{\mathrm{a}}$ & wind velocity \\
\hline$W_{\mathrm{c}}$ & water content: \% \\
\hline$\beta$ & $\begin{array}{l}\text { fatigue coefficient } 2 \text { of the material (Tseng and } \\
\text { Lytton, 1989) }\end{array}$ \\
\hline$\beta_{1}$ & calibration factor \\
\hline$\beta_{\mathrm{g}}$ & aerodynamic diffusion constant \\
\hline$\delta_{\mathrm{p}, \mathrm{tr}}$ & $\begin{array}{l}\text { pavement permanent settlement due to traffic plus } \\
\text { environment }\end{array}$ \\
\hline$\varepsilon$ & emissivity \\
\hline$\lambda$ & thermal conductivity \\
\hline & initial self-weight deformation of the layer $i$ \\
\hline$\varepsilon_{0, \mathrm{sw}}^{i}(t)$ & $\begin{array}{l}\text { current layer deformation due to self-weight of the } \\
\text { layer } i\end{array}$ \\
\hline$\varepsilon_{\mathrm{p}, \mathrm{tr}}^{i}$ & $\begin{array}{l}\text { total plastic strain of the sublayer due to traffic plus } \\
\text { environment }\end{array}$ \\
\hline$\varepsilon_{\mathrm{v}, \mathrm{tr}}^{i}$ & $\begin{array}{l}\text { traffic-induced vertical deformation from pseudo- } \\
\text { static analysis }\end{array}$ \\
\hline$\varepsilon_{\mathrm{o}}$ & $\begin{array}{l}\text { fatigue coefficient } 1 \text { of the material (Tseng and } \\
\text { Lytton, 1989) }\end{array}$ \\
\hline$\varepsilon_{\mathrm{r}}$ & $\begin{array}{l}\text { strain imposed in the laboratory to calculate fatigue } \\
\text { coefficients }\end{array}$ \\
\hline$\mu_{1}$ & liquid viscosity \\
\hline$\rho$ & $\begin{array}{l}\text { fatigue coefficient } 3 \text { of the material (Tseng and } \\
\text { Lytton, 1989) }\end{array}$ \\
\hline$\rho_{\mathrm{va}}^{\mathrm{atm}}$ & atmospheric water vapour density \\
\hline$\rho_{\mathrm{v}}$ & $\begin{array}{l}\text { atmospheric vapour density at the boundary } \\
\text { elements }\end{array}$ \\
\hline$\rho_{\mathrm{va}}$ & atmospheric vapour density \\
\hline & liquid density \\
\hline
\end{tabular}

\section{Introduction}

High-speed train (HST) railway lines (i.e. for trains travelling at speeds above $250 \mathrm{~km} / \mathrm{h}$ ) play an increasing role in worldwide transportation systems. Such lines are particularly demanding in terms of structural robustness and service levels. Ballasted and ballastless tracks are both in use for high-speed lines. Ballasted tracks generally require a smaller initial investment but more intensive maintenance than ballastless tracks (Esveld, 2010).

One of the main drivers of maintenance operations are track geometrical requirements. Movements of the foundation and the infrastructure are reflected on the track. In the ballasted case, the superstructure itself is also a major source of track settlement, mostly through mechanical degradation of the ballast (Indraratna et al., 2011). Regular tamping is then necessary and is used to correct for all settlements, not just those that are ballast induced. Tamping to correct settlement is not an option, however, in the case of a slab track, leading to the widespread belief (Ando et al., 2001; Melis, 2006) that the slab-track system is incompatible with railway earthworks or embankments of any considerable height or with any other circumstances that might cause post-construction settlement of significant magnitude in the platform. That view is too pessimistic.

Within limits, foundation- or infrastructure-originated settlement can also be accommodated by slab-mounted tracks. Several slabtrack systems are able to correct for settlements of up to $70-80 \mathrm{~mm}$, either by adjusting the relative rail-slab position (Vossloh, 2010) or by correcting the position of the plate itself raising it with mortar or resin (Porr Bau $\mathrm{GmbH}, 2012$ ). Also in this respect, it is important to distinguish between continuous concrete systems, cast in place, and discontinuous systems with precast slabs. Whereas continuous systems are very sensitive to longitudinal settlement, precast-slab systems, such as the Shinkansen system widely used for HST lines in Japan, have much larger structural tolerances (Bastin, 2005; Dueñas, 2010; Esveld, 2010). A precast slab-track system can be then designed so that settlement limitations are those derived from rail traffic service quality.

It is nevertheless true that having eliminated ballast as a source of maintenance problems, a slab track design will benefit from limiting any other source of post-construction settlement. Postconstruction settlement of a railway platform can originate either in the foundation natural ground or within the earthworks used to build the platform itself. Generally speaking, designers are fully aware of the need to examine foundation settlements and have many tools to evaluate them and, if so required, to propose remedial actions - for example by soil improvement.

The situation is very different when settlements due to the earthwork itself are considered. Such settlements are due to traffic loads and self-weight acting on a compacted soil whose mechanical response is strongly dependent on its saturation degree. Even if correctly specified and controlled, the ascompacted saturation gives only the initial state of the fill. During its service life, that initial state will change as the fill exchanges water with its surroundings and, in particular, with the atmosphere. It appears then that an appropriate evaluation of the soil-atmosphere interaction is central for the design of embankments supporting slab-track high-speed lines.

The crucial role of soil-atmosphere interactions in a variety of geotechnical problems has long been recognised (Blight, 1997; Gens, 2010). Within this area, several studies have focused on the particular case of railway infrastructure (Briggs et al., 2013; Ferreira and Teixeira, 2012; Ferreira et al., 2011; Gitirana and Fredlund, 2005; Rouainia et al., 2009; Sánchez et al., 2014). With few exceptions (Ferreira and Teixeira, 2012; Ferreira et al., 2011) these studies have emphasised atmospheric effects on strengthdriven problems (slope stability) rather than stiffness and settlement. None of the previous studies considered the case of slab-track high-speed railways, where partial or total fill impermeabilisation may prove cost effective when compared with some current alternatives (e.g. the elevated bridge foundations that are dominant in some Chinese lines; Sun et al., 2013).
1 
This work describes numerical analyses performed to estimate the settlement induced by exposure to the atmosphere of a compacted fill supporting a slab-track operational high-speed line over a period of 20 years, using for this a real climate series from two sites with different climatic characteristics. The impact of several protective measures (impermeable membranes of various dispositions, freedraining base) on the cumulative settlement is analysed. The next section explains the methodology that was devised for the purpose, then the numerical model inputs and characteristics are described, after which some results of the model are presented and discussed.

\section{Methodology}

The general framework of the analysis is inspired by the current American Association of State Highway and Transportation

Q8 Officials (Aashto) mechanistic-empirical design guide for pavements (NCHRP, 2004). This guide incorporated systematically the effects of the environment - precipitation, temperature, freezethaw and so on - on material properties (Zapata et al., 2007). For instance, one of the pavement designs checks for flexible pavements proposed in that guide is that of subgrade cumulative deformation under traffic loads. That computation takes the form of a classic fatigue analysis, in which initial damage - that is, settlement - is amplified as a function of traffic. For granular layers the Aashto method proposes an explicit dependency of the fatiguelaw coefficients on the water content of the layer. Separately, and for the purpose of analytical computation of pavement structures, Aashto also proposes a damage-like environmental correction factor $\left(F_{\mathrm{u}}\right)$ that is used to adjust resilient modulus values as a function of their saturation state. The essential aspects of these Aashto formulations are described in the following section.

Aashto also proposes a variety of simplified methods to evaluate the evolution of relevant soil environmental variables at a given site as a function of relevant climatic conditions at the site. Those simplified methods are discarded here, using instead a specific hydrothermal numerical analysis taking into account fill-atmosphere interaction to obtain the required spatial and temporal evolution of hydric conditions within the fill. The method uses to compute fill-atmosphere interaction is described in the section 'Fill-atmosphere interaction'. This combination of the Aashto method with numerical

Q9 thermo-hydro (T-H) analysis was also used by Ferreira and Teixeira (2012), although they applied it only to traffic-induced settlement.

Like a classic fatigue calculation, the formulation requires also an initial substructure deformation that is modified according to traffic repetition and/or changes of moisture content in the substructure. This is obtained using a purely mechanical finite-element (FE) analysis, as explained in the section 'Initial strain computation'.

\section{Long-term settlement computation}

Traffic load-induced settlement

Aashto proposes a one-dimensional model to compute road surface settlement at any given period during the lifetime of the structure. Settlement is obtained by integrating the permanent deformation of each individual layer as
1. $\delta_{\mathrm{p}, \mathrm{tr}}=\sum_{i=1}^{\mathrm{n}_{\text {sublayers }}} \varepsilon_{\mathrm{p}, \mathrm{rr}}^{i} h^{i}$

where $\delta_{\mathrm{p}, \mathrm{tr}}$ is the surface permanent settlement, $\varepsilon_{\mathrm{p}, \mathrm{tr}}^{i}$ is the total plastic strain of the sublayer $i$ and $h^{i}$ is the thickness of the sublayer. The permanent deformation for each layer $\left(\varepsilon_{\mathrm{p}, \mathrm{tr}}^{i}\right)$ is accumulated as a function of rail traffic up to time $t$

2. $\varepsilon_{\mathrm{p}, \mathrm{tr}}^{i}(t)=\int_{0}^{t} A\left(N, W_{\mathrm{c}}\right) \varepsilon_{\mathrm{v} 0, \mathrm{tr}}^{i} \mathrm{~d} t$

where $\varepsilon_{\mathrm{v} 0 \text {,tr }}^{i}$ is the vertical deformation due to traffic obtained with the pseudo-static mechanical model (see 'Initial strain computation' section), $A\left(N, W_{\mathrm{c}}\right)$ is an amplification factor that depends on traffic repetitions $N$ and $W_{\mathrm{c}}$ is the water content (\%). This amplification factor follows from a proposal of Tseng and Lytton (1989), recalibrated later for the Aashto guide (Zapata et al., 2007)

3. $A\left(N, W_{\mathrm{c}}\right)=\beta_{1}\left(\frac{\varepsilon_{\mathrm{o}}}{\varepsilon_{\mathrm{r}}}\right) e^{-(\rho / N)^{\beta}}$

where the different fatigue coefficients are expressed by the following set of empirical relations

4. $\log \beta=-0 \cdot 61119-0 \cdot 017638 W_{\mathrm{c}}$

5. $\left(\frac{\varepsilon_{\mathrm{o}}}{\varepsilon_{\mathrm{r}}}\right)=\frac{\left[e^{(\rho)^{\beta}} a_{1}\right]+\left[e^{\left(\rho / 10^{9}\right)^{\beta}} a_{9}\right]}{2}$

6. $C_{0}=\ln \left(\frac{a_{1}}{a_{9}}\right)$

7. $\rho=10^{9}\left\{\frac{C_{0}}{\left[1-\left(10^{9}\right)^{\beta}\right]}\right\}^{1 / \beta}$

where $a_{1}=0 \cdot 15$ and $a_{9}=20$. The calibration factor $\beta_{1}$ is equal to 1.673 for unbound granular bases, while it is equal to 1.35 for all subgrade soils. Water contents as a function of time and space for the fill materials are obtained from the coupled T-H analysis described in the section 'Fill-atmosphere interaction'.

\section{Self-weight settlements}

To estimate settlements induced by self-weight coupled to moisture changes, an approximation that incorporates the empirical experience gathered in the Aashto design code with respect to the apparent stiffness variations induced by moisture 
changes is employed. In particular, Aashto gives an empirically based equation that describes the evolution of resilient modulus $\left(M_{\mathrm{r}}\right)$ with the evolution of saturation degree

$$
\begin{aligned}
\log \left(\frac{M_{r}}{M_{r, 0}}\right) & =\log \left(F_{\mathrm{u}}\right) \\
& =a+\frac{b-a}{1+\exp \left[\ln (-b / a)+k_{\mathrm{m}}\left(S_{\mathrm{I}}-S_{\mathrm{I}, 0}\right)\right]}
\end{aligned}
$$

Q12 where $F_{\mathrm{u}}$ is the environmental adjustment factor, $S_{1}$ and $S_{1,0}$ are the current and initial degrees of saturation respectively, while $a$, $b$ and $k_{\mathrm{m}}$ are parameters (see Table 1).

Here the same relationship is used to describe the evolution of elastic parameters of the substructure to determine the self-weight deformation. Again, the evolution of degree of saturation is obtained with the separate $\mathrm{T}-\mathrm{H}$ finite-element method (FEM) simulation described in the following section. Assuming the vertical stress due to self-weight as constant, it is then possible to write that

$\left\{\begin{array}{l}\sigma^{i}=E_{0}^{i} \varepsilon_{\mathrm{v} 0, \mathrm{sw}}^{i} \\ \sigma^{i}=E^{i} \varepsilon_{\mathrm{v}, \mathrm{sw}}^{i}\end{array}\right.$

Hence

10. $\varepsilon_{\mathrm{v}, \mathrm{sw}}^{i}=\frac{E_{0}^{i}}{E^{i}} \varepsilon_{\mathrm{v} 0, \mathrm{sw}}^{i}=\frac{1}{F_{\mathrm{u}}} \varepsilon_{\mathrm{v} 0, \mathrm{sw}}^{i}$

where $t$ is time starting from end of construction, the apex indicates the layer $i, E_{0}$ and $E$ are the initial and current Young's moduli respectively, $\varepsilon_{\mathrm{v} 0, \mathrm{sw}}^{i}$ is the initial vertical self-weight deformation of the layer $i$ and $\varepsilon_{\mathrm{v}, \mathrm{sw}}^{i}(t)$ is the current layer vertical deformation induced by the coupling of self-weight and moisture variations. As for the traffic load case, following Equation 1 the sum of this deformation multiplied by the layer thickness gives the self-weight weather-induced total substructure displacement at any given time. The initial deformation values are obtained in a separate mechanical analysis ('Initial strain computation').

\section{Fill-atmosphere interaction}

Code_Bright (Olivella et al., 1996) is a FEM fully coupled code that solves simultaneously the equations of non-isothermal unsaturated flow in deformable soils. It has extensively been validated and applied to solve geotechnical engineering problems of all sorts (Åkesson et al., 2009; Ferreira et al., 2011; Gens et al., 2007; Sánchez et al., 2015; Vaunat and Gens, 2005; Villarraga et al., 2014). Although Code_Bright handles thermo-hydro-mechanical (THM) problems generally; in this work it is used to solve only the T-H problem by assuming a porous rigid material. Even in this restricted operation mode, the code can represent phenomena such as $(a)$ water flow through unsaturated layers, $(b)$ run-off of superficial water, $(c)$ penetration and infiltration of rainwater, $(d)$ evapotranspiration, $(e)$ capillary rise from the foundation level and $(f)$ temperature evolution in the fill.

A detailed account of the implementation of atmospheric boundary conditions in Code Bright can be found elsewhere (Samat, 2015; Vaunat, 2013). In essence, the boundary condition is imposed as fluxes of air, water and energy deduced from the atmospheric data and the model state near the boundary. In this work the non-evaporative gas flow through the boundary was neglected, leaving only the water and energy fluxes to be specified.

\begin{tabular}{cccc}
\hline Property $\quad$ Model & Form layer & $\begin{array}{c}\text { Embankment } \\
\text { top }\end{array}$ & $\begin{array}{c}\text { Embankment } \\
\text { core }\end{array}$
\end{tabular}

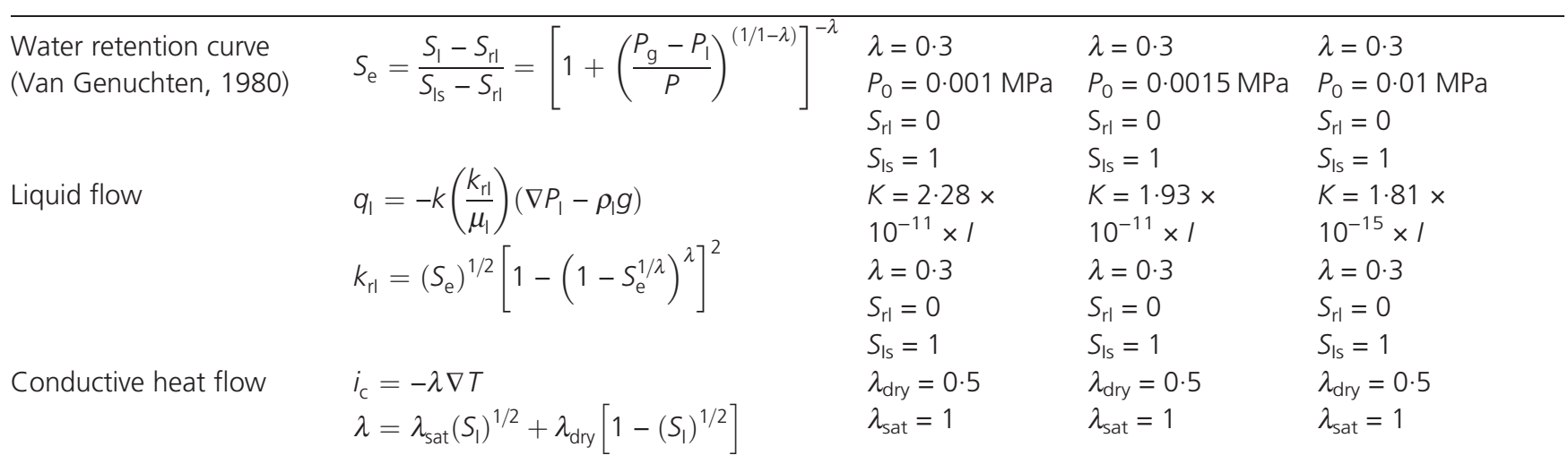




\section{Water flux at the atmospheric boundary}

In general, the flux of water $j_{\mathrm{w}}$ is considered as the sum of precipitation $P_{\mathrm{r}}$, evaporation $j_{\mathrm{E}}$, flux of vapour advected by air $j_{\mathrm{g}}^{\mathrm{W}}$ and surface run-off $j_{\mathrm{sr}}$. In this case, the advective flux of vapour $j_{\mathrm{g}}^{\mathrm{w}}$ is neglected and therefore

11. $j_{\mathrm{w}}=P_{\mathrm{r}}+j_{\mathrm{E}}+j_{\mathrm{sr}}$

Surface run-off is activated by saturation $\left(P_{1}>P_{\text {ga }}\right)$ and driven by positive soil water pressure. The evaporative flux $j_{\mathrm{E}}$ is proportional to the difference in atmospheric water vapour density $\left(\rho_{\text {va }}^{\mathrm{atm}}\right)$ and the atmospheric vapour density at the boundary elements $\left(\rho_{\mathrm{v}}\right)$ computed from relative humidity data

12. $j_{\mathrm{E}}=\beta_{\mathrm{g}}\left(\rho_{\mathrm{va}}^{\mathrm{atm}}-\rho_{\mathrm{v}}\right)$

Q16 where $\beta_{\mathrm{g}}$ is an aerodynamic diffusion coefficient, a function of the wind velocity $v_{\mathrm{a}}$, which is von Karman's constant, the roughness length and the height at which $v_{\mathrm{a}}$ and $\rho_{\mathrm{va}}^{\mathrm{atm}}$ are measured (Louis, 1979). To represent a membrane at a boundary, $P_{\mathrm{r}}$ and $j_{\mathrm{E}}$ are set to 0 .

\section{Energy flux at the atmospheric boundary}

The total energy flux $j_{\mathrm{e}}$ is the sum of net solar radiation $R_{\mathrm{n}}$, sensible heat $H_{\mathrm{s}}$ and convective (latent) $H_{\mathrm{c}}$ heat fluxes

13. $j_{\mathrm{e}}=R_{\mathrm{n}}+H_{\mathrm{s}}+H_{\mathrm{c}}$

The radiation that penetrates the ground results from the balance of the direct solar short-wave radiation $\left(R_{\mathrm{s}}\right)$ - net of albedo reflection - the long-wave atmospheric radiation absorbed by the ground $\left(R_{\mathrm{a}}\right)$ and the radiation emitted by the ground $\left(R_{\mathrm{g}}\right)$

14. $R_{\mathrm{n}}=\left(1-A_{\mathrm{I}}\right) R_{\mathrm{s}}+\varepsilon R_{\mathrm{a}}-R_{\mathrm{g}}$

where $A_{1}$ is the ground albedo and $\varepsilon$ is the atmosphere emissivity. They are considered functions of the saturation ratio $S_{\mathrm{r}}$. In the absence of direct measurements, $R_{\mathrm{S}}$ is computed from average sun radiation $\left(1376 \mathrm{~W} / \mathrm{m}^{2}\right)$, cloud index, local time and geographical position. $R_{\mathrm{a}}$ and $R_{\mathrm{g}}$ are calculated by using the Stefan-Boltzmann law and for $R_{\mathrm{a}}$ the atmospheric partial vapour density.

Sensible heat flux is driven by the difference between the atmospheric temperature $\left(T_{\mathrm{a}}\right)$ and the temperature of the soil $\left(T_{\mathrm{s}}\right)$

15. $H_{\mathrm{s}}=\beta_{\mathrm{g}} \rho_{\mathrm{a}} C_{\mathrm{a}}\left(T_{\mathrm{a}}-T_{\mathrm{s}}\right)$

where $C_{\mathrm{a}}$ and $\rho_{\mathrm{a}}$ are respectively the specific heat and the density of air and $\beta_{\mathrm{g}}$ is the same aerodynamic diffusion coefficient mentioned earlier.
Finally, for this case in which air flow through the boundary is neglected, convective heat flux is computed as

16. $H_{\mathrm{s}}=e_{\mathrm{v}} j_{\mathrm{E}}+e_{\mathrm{w}}\left(P-j_{\mathrm{sr}}\right)$

where $e_{\mathrm{v}}$ is the internal energy of vapour water and $e_{\mathrm{W}}$ is that of liquid water.

The formulation makes clear that water and energy fluxes at the boundary are coupled between themselves and with the state (temperature, suction) inside the soil body. The obtained solution represents an estimate of actual evaporation, limited by soil suction. This is more realistic than using Penman potential evaporation as noted by Vardon et al. (2015).

\section{Initial strain computation}

To determine the initial strains $\varepsilon_{\mathrm{v} 0 \text {,sw }}$ (Equation 10), a staged construction elasto-plastic mechanical analysis is performed using a commercial FE code (Plaxis 2D) to determine the initial selfweight deformation of the embankment. By using the same model, a pseudo-static distributed load of $2.4 \mathrm{kN} / \mathrm{m}$ (Ferreira et al., 2011) is later applied in correspondence of the rail track on 1.435 -m length to obtain the initial strain due to traffic $\varepsilon_{\mathrm{v} 0 \text {,tr }}$ (Equation 2). In these analyses, all the materials were represented using a Mohr-Coulomb constitutive model.

\section{Model definition}

\section{Geometry}

The geometry of the embankment cross-section is represented in Figure 1 together with the boundary conditions and the physical processes, involving water and temperature transfers, which are considered in the numerical simulation.

According to UIC (2008), a slab-track system on earthwork comprises three subsystems, namely the track components; the supporting structure, which comprises an asphalt or concrete layer and a hydraulically bonded base layer; and the earthwork, including the form layer, the top of the embankment and the embankment core. Following indications of the Spanish highspeed railway design standards (Adif, 2011, 2012), the form layer and the embankment top layer are given thicknesses of 0.6 and $1.0 \mathrm{~m}$ respectively, and the external slope of the embankment is $2 \mathrm{H} / 1 \mathrm{~V}$. As indicated in Figure 1, the total embankment height is varied, being equal to $10 \mathrm{~m}$ in most cases and to $5 \mathrm{~m}$ in others.

The slab track and its supporting structure are present in all analysis and represented as an impermeable boundary. They are activated 6 months after the simulation starts, to represent typical construction delays between infrastructure and superstructure. Depending on the analysis, impermeable membranes are disposed in different positions alongside the embankment core perimeter (see Figure 2). All these impermeable boundaries impede water flux but are open to heat exchange. 


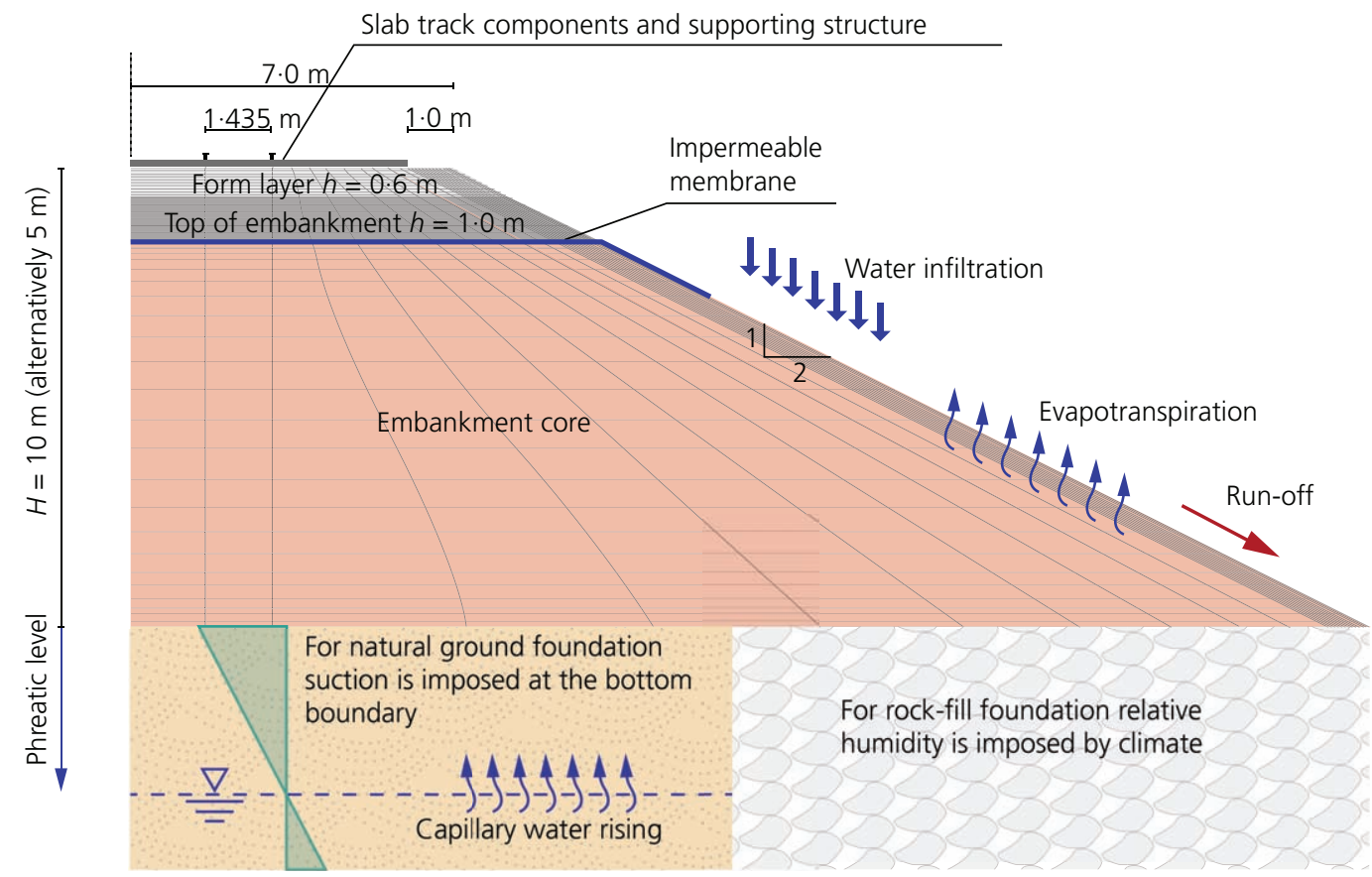

Figure 1. Two-dimensional FE model: hydrothermal loading, mesh and boundary conditions
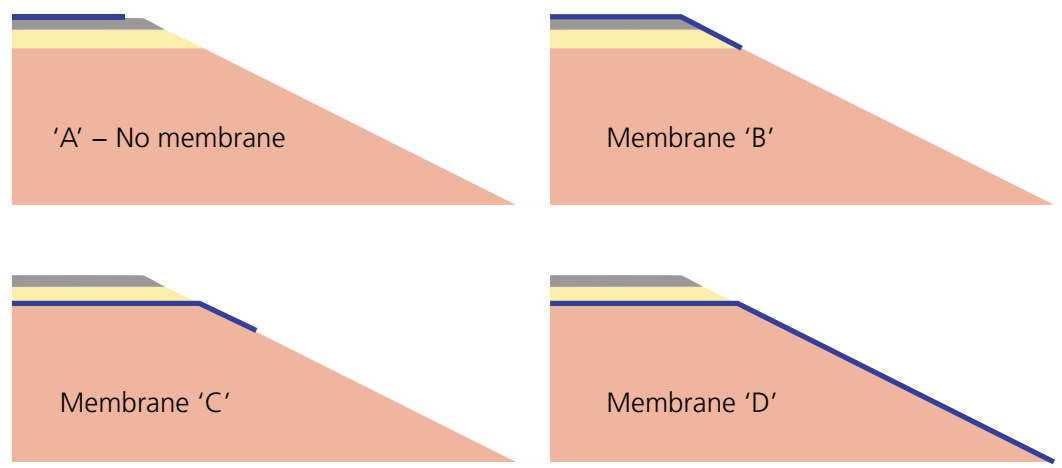

Figure 2. Sketch showing the different locations of impermeable membranes that have been considered in the cases investigated. Location A describes the impervious behaviour of the slab-track components and supporting structure

Foundation materials are not represented directly in the model. Instead, simplified boundary conditions are imposed at the bottom boundary to represent three different scenarios (see Figure 1), namely

(a) constant suction of $20 \mathrm{kPa}$, to represent an embankment overlying soils with a shallow water table

(b) constant suction of $150 \mathrm{kPa}$, to represent an embankment overlying soils with a deep water table

(c) atmospheric relative humidity (but no precipitation or radiation), to represent an embankment supported by a rock- fill layer; rock-fill layers up to $2 \mathrm{~m}$ thick are frequently employed in new railway lines to replace upper soft soils and/ or improve drainage.

It is recognised that, even for a fixed water table depth, the natural suction profile that develops between the groundwater level (GWL) and the ground surface beneath the embankment would change, depending on the water table depth, the nature of the foundation soils, the climatic conditions and the eventual presence of any nearby construction such as buildings, pavements or earthworks (McKeen, 1985). Simulation of these effects is clearly 
Substructure layer $\quad \gamma_{\text {dry: }}: \mathrm{kN} / \mathrm{m}^{3} \quad \gamma_{\text {sat: }}: \mathrm{kN} / \mathrm{m}^{3} \quad E^{\prime}: \mathrm{MPa} \quad v \quad \phi^{\prime}:{ }^{\circ} \quad C^{\prime}: \mathrm{kPa} \quad L_{\mathrm{L}} \quad l_{\mathrm{P}} \quad W_{\mathrm{opt}}: \% \quad \mathrm{CBR} \quad S_{\mathrm{r}:}: \%$ Initial suction: $\mathrm{kPa}$

\begin{tabular}{lrllllllllllll}
\hline Form layer & $20 \cdot 0$ & $22 \cdot 3$ & 50 & 0.33 & 33 & 10 & - & - & $18 \cdot 2$ & 25 & 30 & 20 & 50 \\
Embankment top & $20 \cdot 0$ & $22 \cdot 3$ & 50 & 0.33 & 33 & 10 & - & - & $18 \cdot 2$ & 25 & 30 & 15 \\
Embankment core & $17 \cdot 8$ & $21 \cdot 1$ & 13 & 0.33 & 30 & 10 & 38 & 15 & 29.9 & 5 & $90 \cdot 6$ & 150
\end{tabular}

Table 2. Identification and mechanical parameters of the different materials in the model

possible (Briggs et al., 2013; Qadad et al., 2012) but would require a larger model and is out of the scope of this work

\section{Materials}

Both the form layer and the embankment top material properties are typical of granular materials used in that role in high-speed lines, whereas the embankment core has the properties of a

Q20 Miocene marly clay $\left(L_{\mathrm{L}}=38 \% ; I_{\mathrm{P}}=15 \%\right)$ from the city of Antequera (Spain) that fulfils standard regulations (Adif, 2012) for railway fill and was considered representative of materials currently employed in embankments for high-speed lines in Spain. The properties considered in this paper for the earthwork layers are presented in Table 2, which also includes the mechanical properties used for the initial strain FE analysis. Modified Proctor compaction laboratory tests were undertaken for the three types of soils, and the initial suction at the compaction optimum water content was estimated according to Ridley and Perez-Romero (1998).

\begin{tabular}{lcc} 
Parameter & Coarse-grained materials & Fine-grained materials \\
\hline$a$ & -0.3123 & -0.5934 \\
$b$ & 0.3 & 0.4 \\
$k_{\mathrm{m}}$ & 6.8157 & $6 \cdot 1324$
\end{tabular}

Table 3. Aashto environmental factor parameters

A Van Genuchten (1980) soil water retention curve (SWRC) for the embankment core material was fitted through several compaction data. For the granular materials (form layer, embankment top), the same Van Genuchten model was used, fitting it to coincide in the compaction range with the SWRC proposed by the Aashto guide for granular layers - the analytical formulation of the Aashto SWRC caused problems in the numerical analysis. Saturated permeability values were available
1

2 3 arid climate at Antequera (red) and wet climate at San Sebastian (light blue) 
Environmental Geotechnics

Volume XXXX Issue EGXXXX
Impermeable membranes for slab-track

settlement mitigation

Pérez-Romero, Ciantia, Arroyo and Vaunat for the core material. Other values of permeability, as well as the values of parameters controlling permeability dependence on saturation and heat flow through the soil (Table 1), were assigned based on previous experience with similar materials.

The Aashto-proposed parameters for the environmental factor formulation are presented in Table 3. Coarse-grained values were used for the embankment top and form layers; fine-grained ones, for the embankment core material.

\section{Climate conditions}

The numerical model considers atmospheric data, during a period of 10 years, of two particular locations within Spain (Antequera and San Sebastian), having markedly different climate regimes (see Figures 3-5). Available estimates of the Thornthwaite index

Q22 (Oteo et al., 1995) would classify Antequera as semi-arid $\left(I_{\mathrm{h}}\right.$ of -20 to -40$)$ and San Sebastian as humid $\left(I_{\mathrm{h}} 60-100\right)$. The climate of Antequera, a city situated in Andalusia at the southern part of the Iberian peninsula, can be described as a temperate climate with a particularly dry period during the summer, and classified as $C s a$ according to the Köppen-Geiger climate classification (Köppen, 1936). The second one corresponds to the city of San Sebastian, placed by the northern coastline of Spain, which is another temperate climate $(C f b)$ but with no dry season during the summer.

The time-varying atmospheric data series which were employed in both cases are summarised in Table 4. The cloud index is used to estimate the radiation in the absence of a direct measure. The available data had daily resolution. However, updating the atmospheric boundary condition every day made the 10-year calculations slow and cumbersome. A trial calculation was made in which a case was run with a daily updating period and another with a weekly updating period, using average weekly climatic data. The results showed no significant difference, and the weekly period was adopted for all the remaining computations.

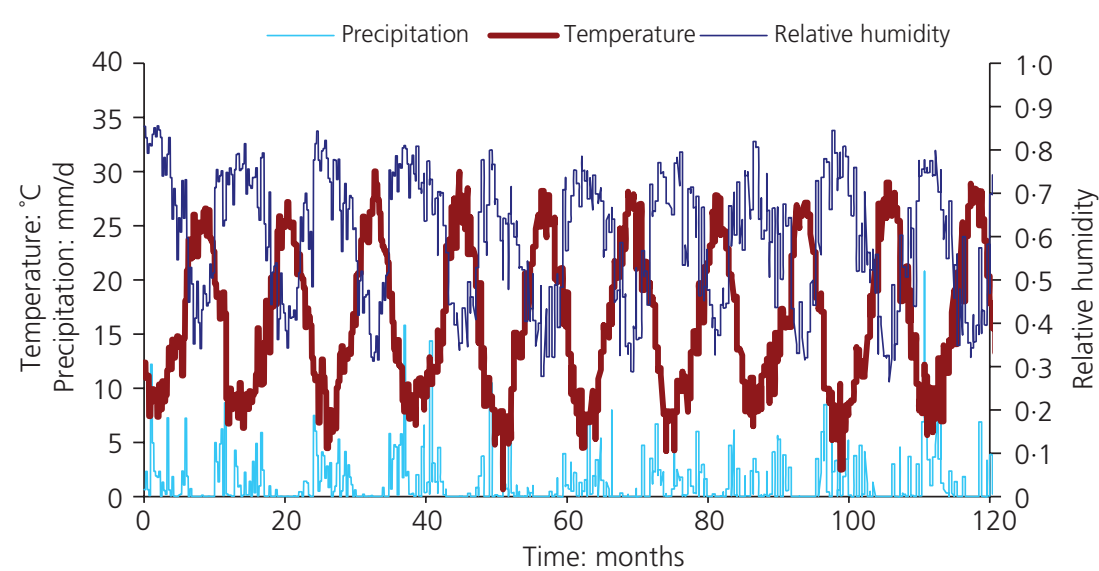

(a)

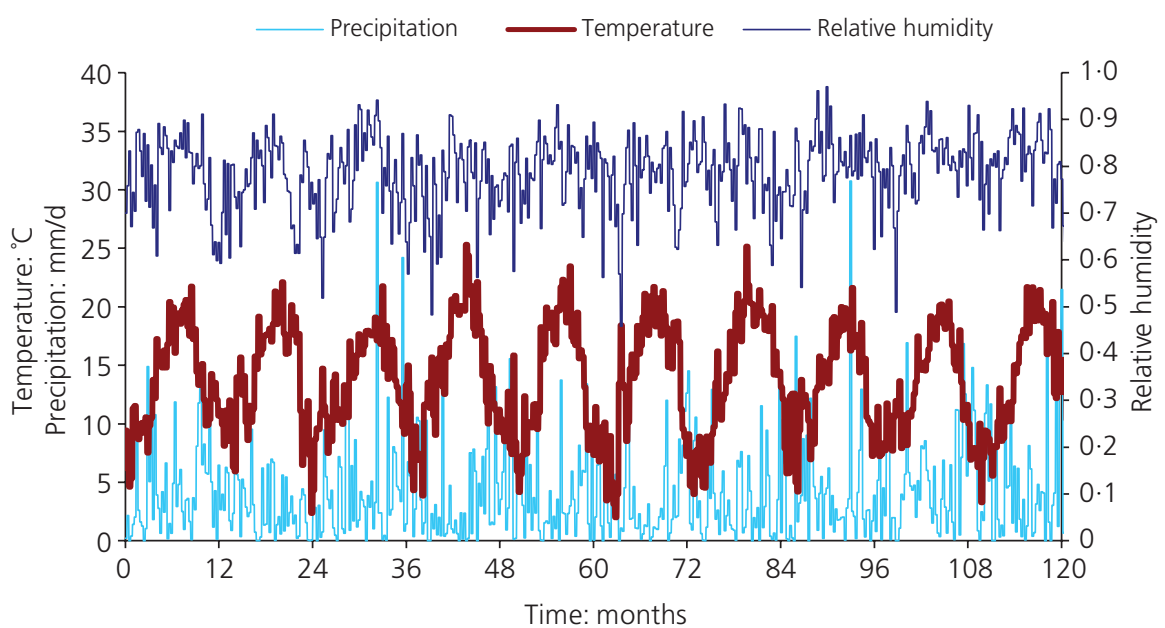

(b)

Figure 4. 10 years of atmospheric data recording in (a) San Sebastian (wet) and (b) Antequera (semi-arid) - precipitation, temperature and relative humidity weekly averages 


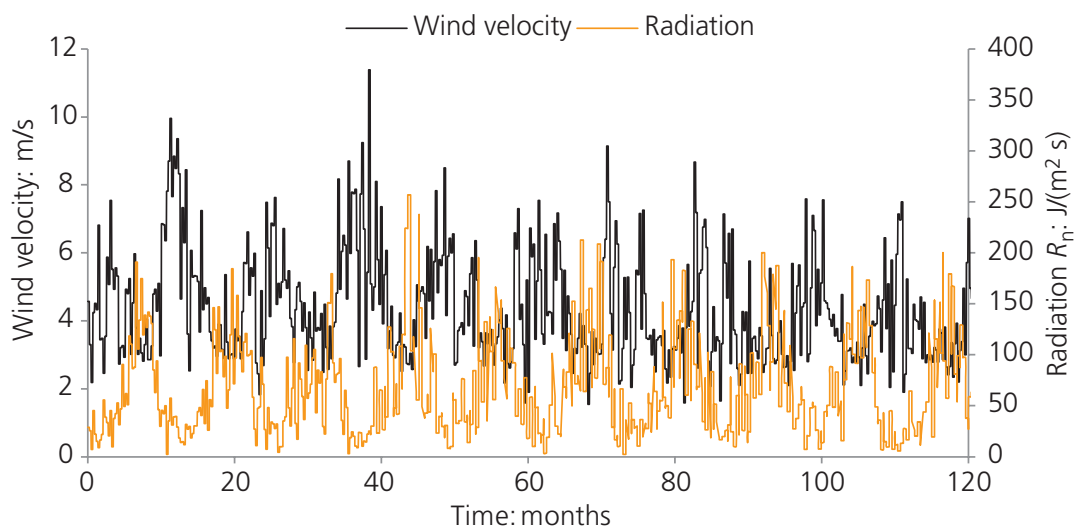

(a)

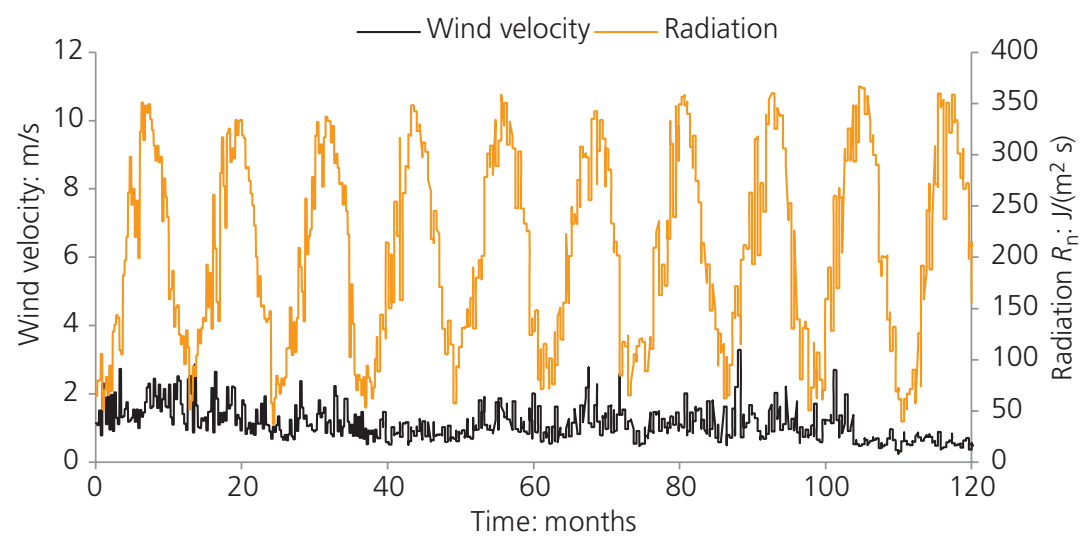

(b)

Figure 5. 10 years of atmospheric data recording in (a) San Sebastian (wet) and (b) Antequera (semi-arid) - wind velocity and radiation

\section{Traffic}

The traffic intensity estimates for a high-speed line provided by Ferreira and Teixeira (2012) were also assumed here. The number of repetitions $N$ were determined assuming a million gross tons (MGT) of $16 \cdot 5$ per year. Such a year's MGT corresponds to 100 HSTs composed of 13 wagons with two axles each, which weighs $17 \mathrm{t}$ per axle. Therefore, the value that will be used as a reference for all the following analyses is $N=270 / \mathrm{d}$.

\section{Analyses performed}

Twelve different cases were analysed as listed in Table 5. The analysis variables include the climatic conditions (semi-arid corresponds to the Antequera case and wet to the San Sebastian one), the total height of the earthwork, the type of bottom boundary condition (suction value at foundation level) and the presence of an impermeable membrane and its location (see Figure 2).

\begin{tabular}{lccc}
\hline Data & Unit & Semi-arid (Antequera) & Wet (San Sebastian) \\
\hline Atmospheric temperature $T_{\mathrm{a}}$ & ${ }^{\circ} \mathrm{C}$ & Yes & Yes \\
Atmospheric gas pressure $P_{\mathrm{ga}}$ & $\mathrm{MPa}$ & No & No \\
Relative humidity $H_{\mathrm{r}}$ & - & Yes & Yes \\
Radiation $R_{\mathrm{n}}$ & $\mathrm{J} /\left(\mathrm{m}^{2} \mathrm{~s}\right)$ & Yes & Not available \\
Cloud index $I_{\mathrm{n}}$ & - & No & Yes \\
Rainfall $P_{\mathrm{r}}$ & $\mathrm{kg} /\left(\mathrm{m}^{2} \mathrm{~s}\right)$ & Yes & Yes \\
Wind velocity $v_{\mathrm{a}}$ & $\mathrm{m} / \mathrm{s}$ & Yes & Yes
\end{tabular}

Table 4. Time-varying atmospheric data employed in the analyses 


\begin{tabular}{|c|c|c|c|c|c|c|c|}
\hline \multirow[t]{2}{*}{ Case ID } & \multicolumn{4}{|c|}{ Model description } & \multicolumn{3}{|c|}{ Settlement after 10 years: $\mathrm{mm}$} \\
\hline & $\begin{array}{l}\text { Embankment height: } \\
\text { m }\end{array}$ & $\begin{array}{l}\text { Membrane } \\
\text { location }\end{array}$ & $\begin{array}{l}\text { Suction at } \\
\text { foundation }\end{array}$ & Climate & $\begin{array}{l}\text { Traffic } \\
\text { loads }\end{array}$ & $\begin{array}{l}\text { Self-weight and } \\
\text { softening }\end{array}$ & Total \\
\hline UMA01 & 10 & A & $20 \mathrm{kPa}$ & Semi-arid & $8 \cdot 4$ & $29 \cdot 0$ & $37 \cdot 4$ \\
\hline UMA02 & 10 & B & $20 \mathrm{kPa}$ & Semi-arid & $8 \cdot 5$ & $15 \cdot 0$ & $23 \cdot 5$ \\
\hline UMA03 & 10 & $C$ & $20 \mathrm{kPa}$ & Semi-arid & 8.6 & $14 \cdot 7$ & $23 \cdot 3$ \\
\hline UMA04 & 10 & $\mathrm{D}$ & $20 \mathrm{kPa}$ & Semi-arid & 8.6 & $14 \cdot 7$ & $23 \cdot 3$ \\
\hline UMA05 & 5 & A & $20 \mathrm{kPa}$ & Semi-arid & $4 \cdot 7$ & 3.9 & $8 \cdot 6$ \\
\hline UMA06 & 5 & $A$ & $20 \mathrm{kPa}$ & Wet & $5 \cdot 7$ & $3 \cdot 9$ & $9 \cdot 6$ \\
\hline UMA07 & 10 & $A$ & $20 \mathrm{kPa}$ & Wet & $8 \cdot 2$ & $35 \cdot 7$ & $43 \cdot 9$ \\
\hline UMA08 & 10 & A & $150 \mathrm{kPa}$ & Semi-arid & $8 \cdot 5$ & $15 \cdot 6$ & $24 \cdot 1$ \\
\hline UMA09 & 10 & C & $20 \mathrm{kPa}$ & Wet & $8 \cdot 6$ & $14 \cdot 6$ & $23 \cdot 2$ \\
\hline UMA10 & 10 & $D$ & $20 \mathrm{kPa}$ & Wet & 8.6 & $14 \cdot 8$ & $23 \cdot 4$ \\
\hline UMA11 & 5 & $A$ & Atmospheric & Semi-arid & $5 \cdot 7$ & $6 \cdot 9$ & $12 \cdot 6$ \\
\hline UMA12 & 5 & $A$ & Atmospheric & Wet & $5 \cdot 7$ & $6 \cdot 9$ & $12 \cdot 6$ \\
\hline
\end{tabular}

Climate: semi-arid (Antequera); wet (San Sebastian)

Bottom boundary conditions at foundation level: $20 \mathrm{kPa}$ (hydrostatic suction, GWL at 2-m depth); $150 \mathrm{kPa}$ (hydrostatic suction, GWL at 15-m depth); atmospheric suction (granular or rock-fill foundation; no rain, no radiation effects)

Table 5. Description of cases investigated and calculated settlements after 10 years of exposure to the atmosphere

\section{Results: soil-atmosphere interaction}

Influence of climate

The influence of the climate conditions can be appreciated, for

Q23 instance, by comparing the cases UMA01 and UMA07, which represent a case where the embankment is $10 \mathrm{~m}$ high, the water table is high within the foundation and no geomembrane protection

Q24 is placed. In the absence membranes, and cases UMA03 to UMA09 if a membrane is disposed at a given location.

The results (Figure 6) show two clearly separate influences on the hydric state of the embankment core. On the one hand, a steady intake of water from the lower boundary takes place (the core material compacted suction is significantly below the $20 \mathrm{kPa}$ maintained at the base). On the other hand, the atmospheric effects are felt on the upper levels of the embankment core. In general, the upper layers of the clay fill tend to increase their saturation above the initial $80 \%$ : this happens faster in the wet climate and more steadily with little or no reversals - note instead the reversals at 2-3 and 7-8 years in the drier case.

The granular layers show a faster response to the climatic conditions and, at the embankment axis, maintain a reduced saturation level (20-50\%) during the simulation. Note that after installation of the slab track, 6 months after the beginning of the simulation, these layers have direct contact only with the atmosphere on the embankment side. Within this general pattern, the climate effects are

Q25 clear. In the drier climate, there are only episodic increases on saturation, whereas on the more humid climate, short-term oscillations superimpose on a steadily increasing trend.
Influence of the use of impermeable membranes and its location

Figure 7 presents results for cases that have 10-m-high earthwork and low suction at the base, are exposed to a semi-arid climate (cases UMA01, UMA02, UMA03 and UMA04) and have different dispositions of impermeabilisation.

The presence of the membranes does not disturb the slow intake of water from the bottom of the embankment, but changes significantly the influence of the atmosphere. In case UMA02 (Figure 7, second row), the membrane stops the granular layers from exchanging water with the atmosphere, resulting in longterm stabilisation of saturation for the upper layers. Only at those points closer to the slab lower side $(z=10 ; z=9 \cdot 9)$, some small oscillations remain: these are due to thermal effects.

In case UMA03, the membrane separates the upper granular layers from the core. At the embankment axis, the result is that the core does take only water from below and remains completely isolated from the weather, whereas in the upper granular layers, the effects of climate oscillations are felt as saturation-desaturation episodes. Because of the large size of the embankment, the response at the embankment axis in this case is practically identical to that of case UMA04, where the geomembrane isolation is extended to the whole embankment slope.

It is clear that the granular layers of the earthwork (i.e. the form layer and the top of the embankment) act as a preferential path for the water flow from the atmosphere to the embankment core, due to their typical water retention curves (see Figure 8). Indeed, 

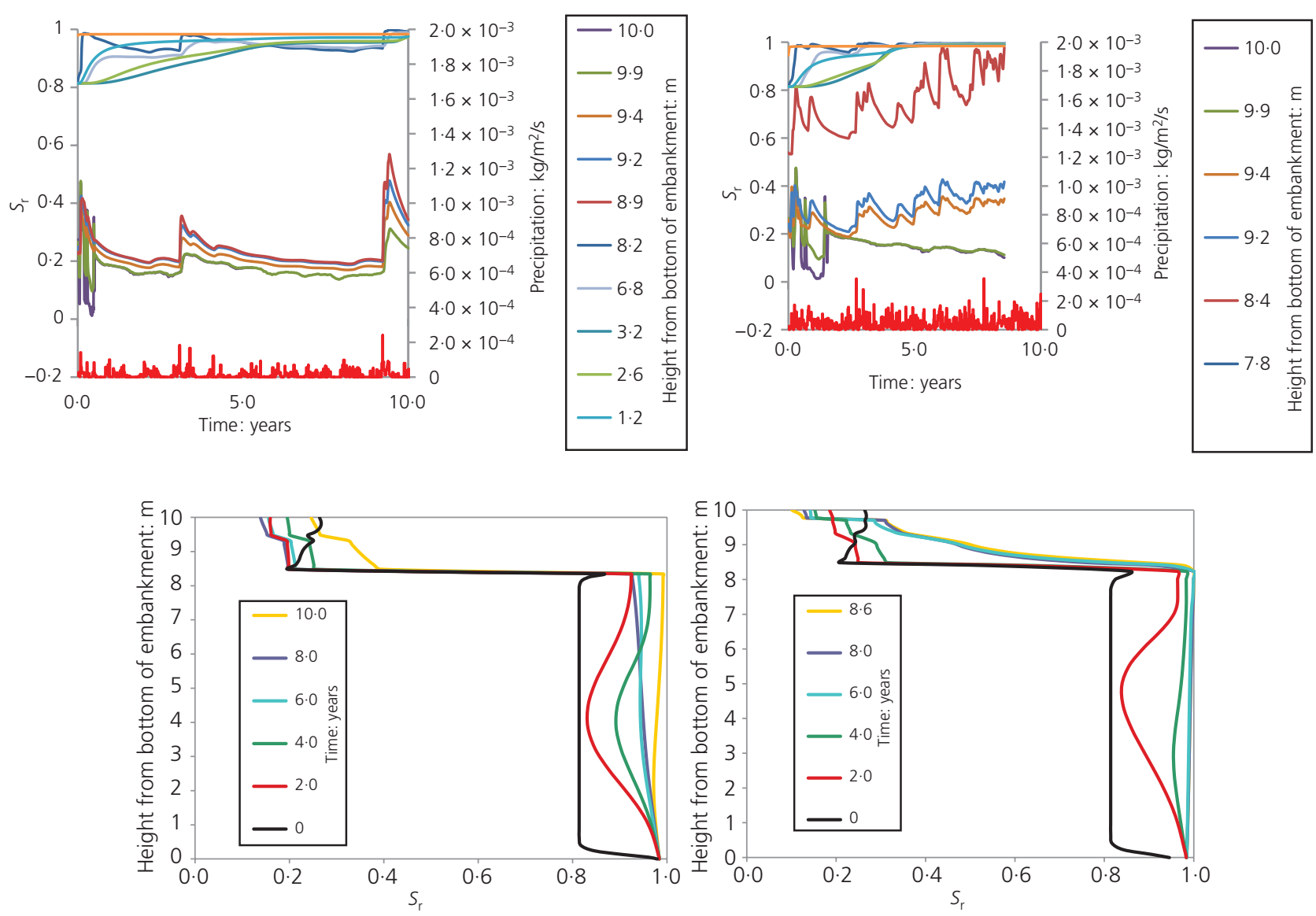

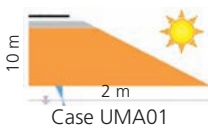

Figure 6. Evolution of fill saturation for simulations UMA01 (left) and UMA07 (right). The upper panels represent saturation evolution beneath the embankment axis at different depths (left axis) and precipitation (right axis). The central panels represent during dry periods the suction values imposed by the atmosphere are high and, as a consequence, the saturation ratio of these granular layers drops dramatically; under these circumstances, the actual permeability of the granular layers is extremely low, hence preventing the flow of water into the earthwork. When it rains, their suction values become very small (a few kilopascals at 50\% saturation) and their permeability rises, making it easy for the water to flow into the lower cohesive layer.

\section{Influence of the suction value-boundary condition at} foundation level

The effect of the boundary condition at the bottom on the hydraulic evolution of the fill is illustrated in Figure 9, comparing results for a 5-m-high embankment with no protective membrane in wet and dry climates, with constant low suction at the base or atmospheric suction (rock-fill foundation). It appears that the bottom boundary condition has more impact on the semi-arid climate (left column) than in the wet one (right column). The wet climate condition at the bottom has almost the same effect on the fill as having a high water table; this is unsurprising, since both conditions are frequently associated. On the other hand, in the semi-arid case, the presence of a coarse layer at the foundation will certainly make the fill drier on average if, for some reason, there is a locally elevated water table.

\section{Influence of the embankment height}

An idea of the effect of this variable can be obtained by comparing the results presented on the first row of Figure 9 with the equivalent ones presented in Figure 6. The smaller embankment has a faster response to the environmental actions, and in 2 years the core is almost fully saturated.

\section{Results: settlement at the fill axis}

Figure 10 presents the time-settlement curves for all cases analysed. Note that in all cases, the settlement computation starts 6 months 
Environmental Geotechnics

Volume $X X X X$ Issue EGXXXX
Impermeable membranes for slab-track

settlement mitigation

Pérez-Romero, Ciantia, Arroyo and Vaunat
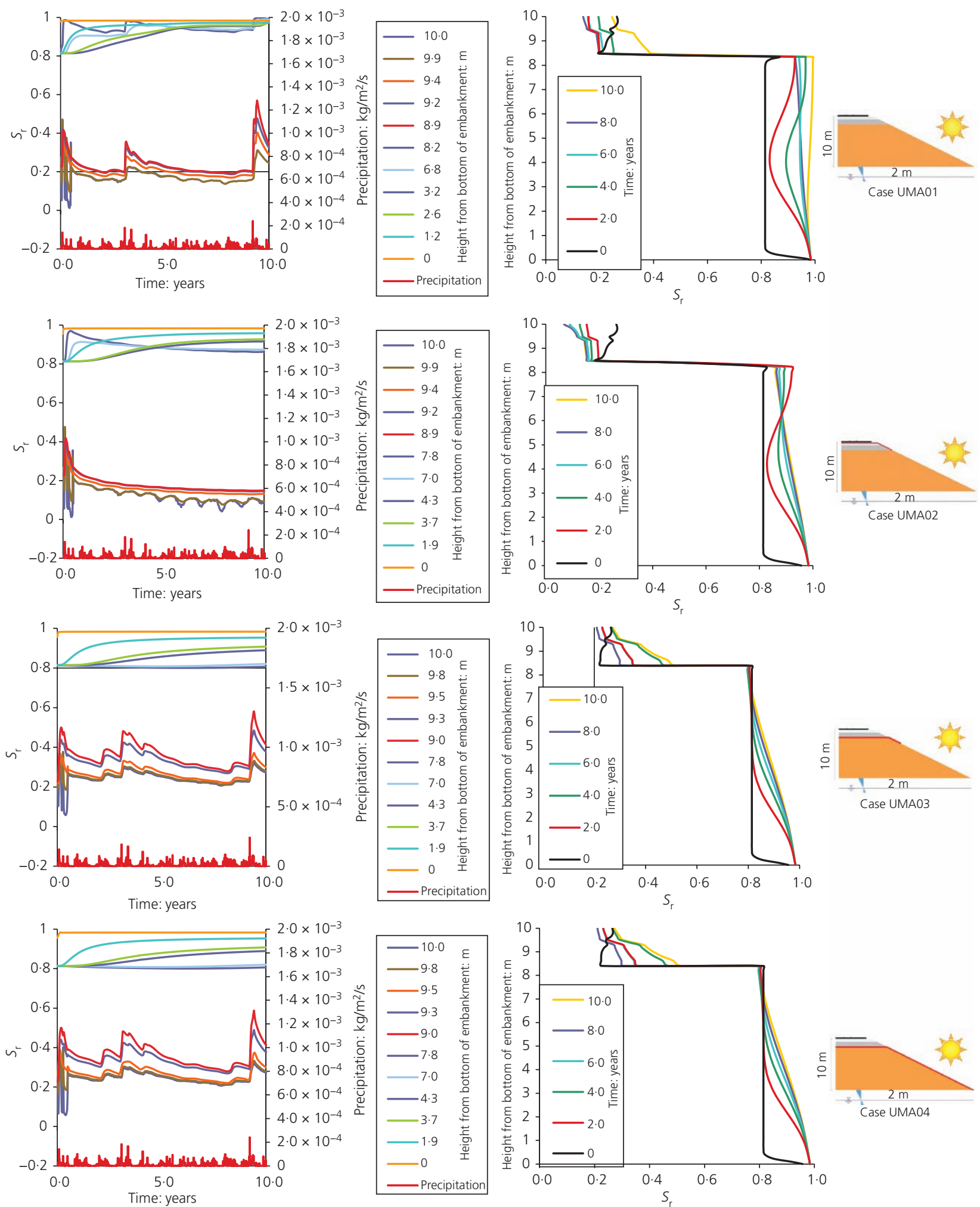

Q27 Figure 7. Calculated values of the saturation ratio: evolution at different positions (left) and spatial distribution after different periods of exposure to the atmosphere (right). From top to bottom: cases UMA01, UMA02, UM03 and UMA04 


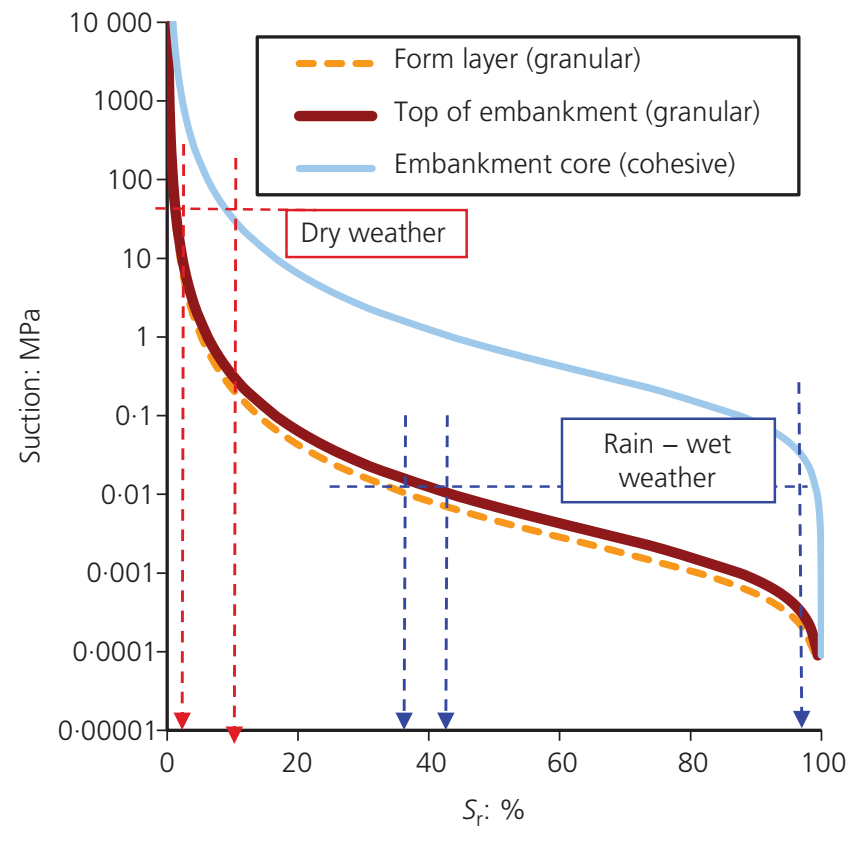

Figure 8. SWRCs, deduced after Van Genuchten (1980), for the three layers of the earthwork. The equilibrium saturation ratio values in the granular layers are always below that in the embankment core; that difference is higher during wet periods than during dry ones

after the simulation started, because only post-slab construction settlement is relevant. Settlement due to traffic loads and that due to self-weight are separately presented. The final values are also reported in Table 4. Inspection of these results shows the following.

(a) The 10-year settlement due to traffic loads varies slightly, the major difference being brought by fill height. Normalised by fill height, all cases lie between $0 \cdot 08$ and $0 \cdot 11 \%$.

(b) The 10-year settlement due to fill self-weight is more sensitive to other variables, besides fill height. Its value normalised by fill height ranges from 0.08 to $0.36 \%$. The larger sensitivity of self-weight settlement follows from the larger volume of soil affected by that load; traffic load-induced settlement is sensitive only to climate effects on the upper layers of the embankment, whereas climate effects on the whole embankment have an influence on self-weight settlement.

(c) Geomembrane protection approximately halves the accumulated self-weight settlement (compare case UMA01 with cases UMA02, UMA03 and UMA04 and case UMA07 against case UMA09 or UMA10).

(d) The different geometries of geomembrane explored have almost no impact on the settlement at the embankment axis. Closer to the fill slope, the results - not presented here - are more sensitive.

(e) For the unprotected cases, exposure to the wet climate results in larger 10-year settlements compared with exposure to the dry climate (UMA01 against UMA07; UMA05 against UMA06). $(f)$ The rate of settlement is also affected significantly by climate conditions: settlement accumulates faster in wet conditions. The semi-arid climate also results in more sudden changes in settlement rate, particularly after heavy rainfall.

( $g$ ) Having a deeper water table does reduce significantly the accumulated 10-year settlement when compared with a shallow water table situation (UMA01 against UMA08).

(h) A rock-fill bottom boundary does impose atmospheric conditions at the base. In the cases analysed, it resulted in slightly increased settlement when compared with the shallow water table situation (UMA05 and UMA06 against UMA11 and UMA12).

\section{Discussion}

Relatively few publications or standards have explicitly established criteria for limiting platform settlement for slab-track systems. Moreover, the reasons behind certain published limit values are sometimes unclear. Thus, Ando et al. (2001) report criteria adopted for the Shinkansen system in Japan. They indicate, in the first instance, that the maximum post-construction settlement of the platform must not exceed $30 \mathrm{~mm}$, which is the maximum limit that the Shinkansen system can accommodate to adjust the vertical position of the rail. Another example can be seen in the criteria adopted in Germany, as reported by Melis (2006), for the Rheda system, which consists of a maximum settlement of $60 \mathrm{~mm}$ and a maximum tilt of $1 / 500$. In this case it is not made clear whether this limitation is imposed by the slabtrack system itself or by operative reasons. In the case of the California High-speed Train Project Design Criteria (CHSRA, 2012), different criteria have been adopted. The maximum remaining or post-construction settlement in the platform is limited to $16 \mathrm{~mm}$, and the curvature associated with the maximum settlement on a section approximately $20 \mathrm{~m}$ long must have a minimum radius of around $4250 \mathrm{~m}$.

Settlement limitation criteria may be derived from operational considerations. Indeed, the geometrical quality of the track has a direct influence on traffic safety, passenger comfort and rolling stock performance. For this reason, certain standards have been set, although their recommendations are not always easy to interpret in terms of settlement limitation. When it comes to describing or characterising the geometrical quality of the track, four levels can be defined (QN1, QN2, QN3 and QN4), the latest one requiring immediate action such as the imposition of speed limits. The track geometry quality standard EN 13803-5:2010 (CEN, 2010) recommends for speeds of $300 \mathrm{~km} / \mathrm{h}$ minimum values of 38200 of curvature radius, which may be lowered in exceptional cases to $12200 \mathrm{~m}$. A more direct limit on settlement may be deduced from EN 14363:2005 (CEN, 2005) and EN 13848-5:2008 (CEN, 2008). Depending on operational speed and wavelength, the limits that require immediate intervention (QN4) range between 25 and $34 \mathrm{~mm}$. Note that none of these limits are specific for slab-track systems.

A summary of the criteria mentioned is presented in Table 6, noting whether the criteria are specific to slab-track systems or whether they are related only to the maintenance of lines and rail 

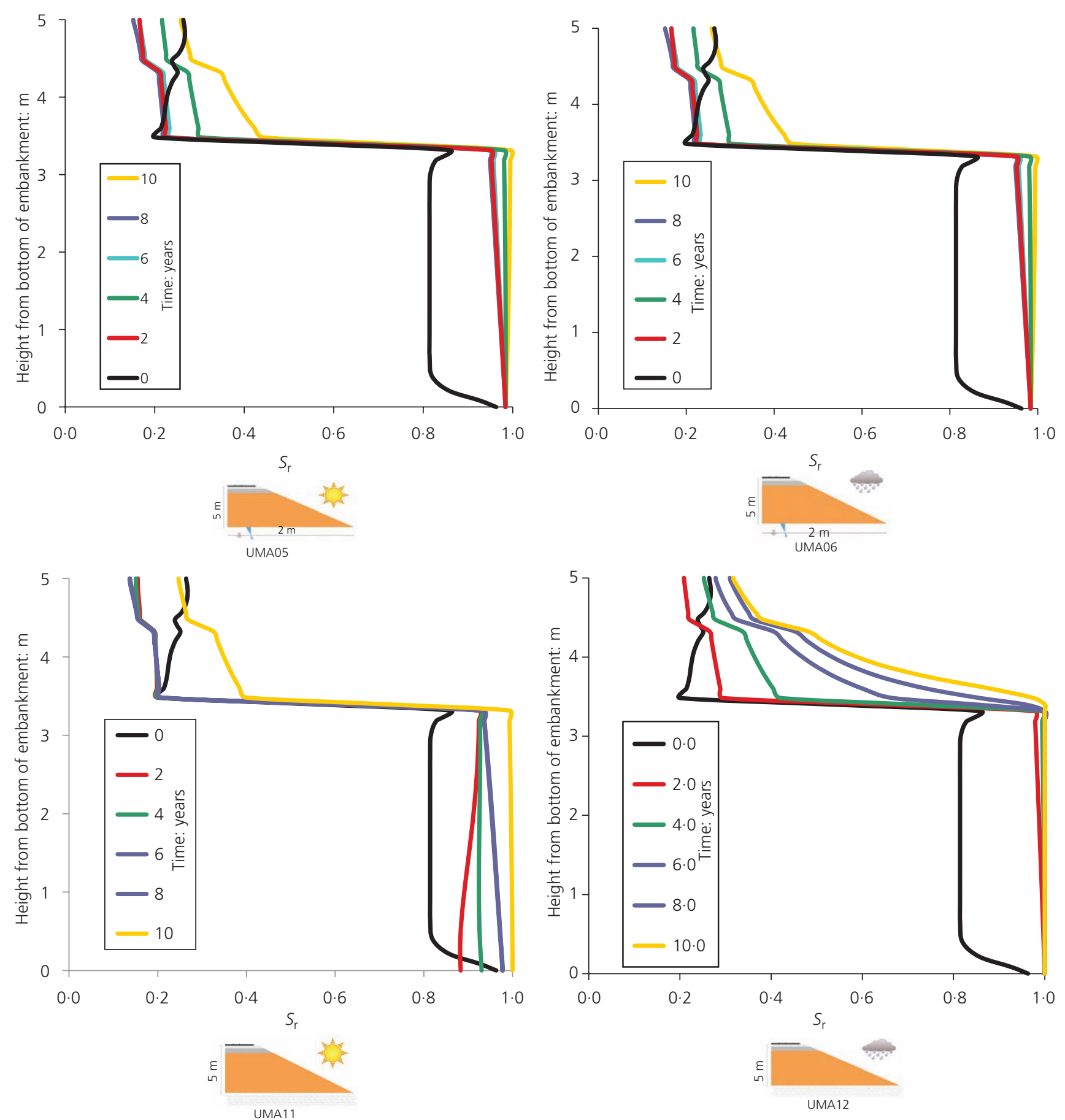

Figure 9. Saturation ratio profiles for two different types of climate (legend indicates time in years): semi-arid (left) and wet climate (right); and boundary conditions at foundation level:

traffic but are not specific to slab-track systems. Comparing these limits with the 10-year accumulated settlement estimated in the computations (Table 5), it appears that in many cases, fill-atmosphere interaction may result in increased maintenance and that avoiding the cost of that maintenance may justify partial or total fill impermeabilisation.
The Aashto methodology has an empirical base, which is being updated continuously (e.g. Cary and Zapata, 2010). In this respect, the method proposed inherits the limits and range of validation of the Aashto expressions that were employed. As for the soil-atmosphere interaction module of Code_Bright, some validation examples are presented by Vaunat (2013) and Samat 

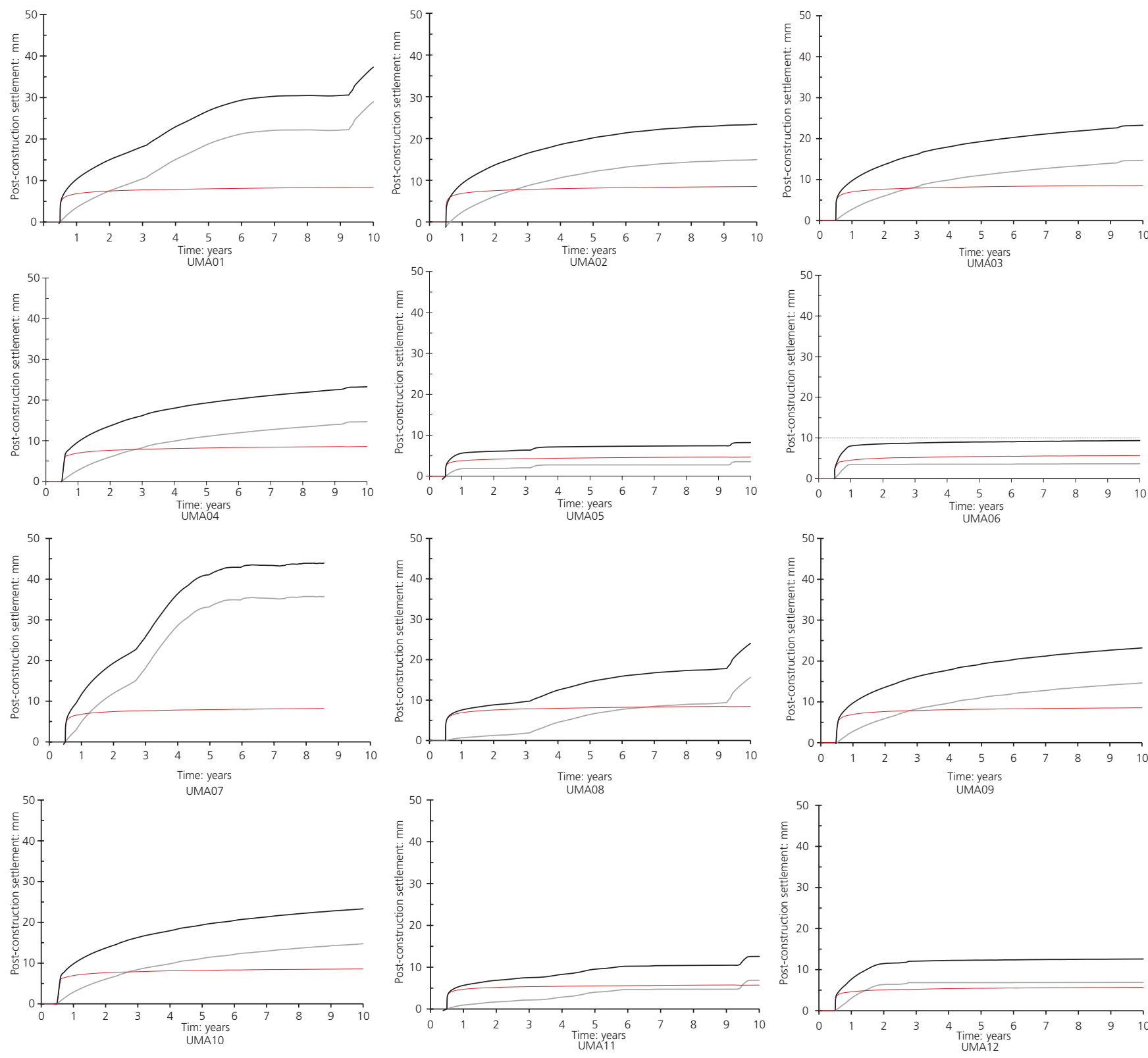

Figure 10. Evolution of calculated settlement (due to softening and self-weight, traffic loads and total settlement) during 10 years of exposure to the atmosphere for the 12 cases investigated

(2015). Despite that, it would be certainly desirable to validate the combined methodology employed here, for instance by long-term monitoring of existing high-speed fills.

In the analysis just presented, a relatively water-insensitive fill material was employed for the embankment fill. Such kind of fill is not always available, and for lesser-quality construction materials, the mechanical consequences of soil-atmosphere interaction may be much larger Although similar analyses and impermeabilisation solutions may also prove effective in those cases, a fully coupled THM study, using an appropriate constitutive model, should be performed. Indeed, constitutive models have been described for some materials on that category, such as swelling soils (Gens and Alonso, 1992), clayey rocks (Alonso et al., 2013; Cardoso et al., 2013) or rock-fill (Oldecop and Alonso, 2007). Finally, it is also worth noting that impermeabilisation using membranes may not be the only solution to prevent rapid humectation of the fills. Appropriate revegetation may offer a more advantageous solution in some circumstances; modelling the effect of such solution is now possible (Samat, 2015; Smethurst et al., 2015) and certainly worthy of further study. 


\begin{tabular}{llcccc}
\hline Source & \multicolumn{1}{c}{ Reference } & $\begin{array}{c}\text { Total settling: } \\
\mathrm{mm}\end{array}$ & $\begin{array}{c}\text { Relative } \\
\text { rotation }\end{array}$ & $\begin{array}{c}\text { Angular } \\
\text { deformation }\end{array}$ & $\begin{array}{c}\text { Equivalent curve } \\
\text { radius: } \mathrm{m}\end{array}$ \\
\hline Shinkansen/Japan & Ando et al. (2001) & $30^{\mathrm{a}}$ & $1 / 1800$ & $1 / 333$ & - \\
Rheda/Germany & DB (1999) apud Melis (2006) & $60^{\mathrm{a}}$ & $1 / 500^{\mathrm{a}}$ & - & - \\
California & CHSRA (2012) & $16^{\mathrm{a}}$ & - & - & $4250^{\mathrm{a}}$ \\
EN 13803-1:2010 & CEN (2010) & - & - & - & $>12200^{\mathrm{b}}$ \\
EN 14363:2005 & CEN (2005) & $25-34^{\mathrm{b}}$ & & \\
\hline
\end{tabular}

${ }^{a}$ Criteria specific to slab-track systems

${ }^{b}$ Criteria related only to the maintenance of lines and rail traffic but are not specific to slab-track systems

Table 6. Criteria established to limit settlement in platforms

\section{Conclusion}

Slab-track-mounted high-speed railways are demanding structures in terms of settlement. Soil-atmosphere interaction may produce non-negligible operational settlement, even when good-quality fills are employed. Partial impermeabilisation of the fill may be advantageous in some cases. Methods such as the one illustrated here, combining a detailed consideration of local climate conditions with relative computational expediency, may prove useful for the design and planning of such works.

\section{Acknowledgements}

This study was undertaken as part of the research project Fastrack (Eco-friendly and Sustainable Slab Track for High-speed Lines), performed between 2013 and 2015, coordinated by Centro de

Q32 Estudios de Materiales y Control de Obra (Cemosa) and supported

Q33 by CDTI and Fonds Européen de Développement Économique et Régional (Feder) EU funds. The authors want particularly to thank Dr Noemi Jiménez from Cemosa for his support during this work. The student M. V. Boas Dinis performed the analysis for models UMA11 and UMA12 as part of her final degree thesis.

\section{Q34 REFERENCES}

Q35 Adif (Administrador de Infraestructuras Ferroviarias) (2011) Instrucciones y Recomendaciones para la Redacción de Proyectos de Plataforma: IGP-1.1 Recomendaciones sobre Desmontes y Rellenos. Adif, Madrid, Spain (in Spanish). Adif (2012) Pliego de Prescripciones Técnicas Tipo para los Proyectos de Plataforma: PGP version 2, Approved June 2012. Adif, Madrid, Spain (in Spanish).

Aemet (Agencia Estatal de Meteorología) and IMP (Instituto de Meteorología de Portugal) (2011) Atlas Climático Ibérico. Aemet, Madrid, Spain (in Spanish).

Åkesson M, Jacinto AC, Gatabin C, Sanchez M and Ledesma A (2009) Bentonite THM behaviour at high temperatures: experimental and numerical analysis. Géotechnique 59(4): 307-318.

Alonso EE, Pinyol NM and Gens A (2013) Compacted soil behaviour: initial state, structure and constitutive modelling. Géotechnique 63(6): 463-478.

Ando K, Sunaga M, Aoki H and Haga O (2001) Development of slab tracks for Hokuriku Shinkansen Line. Quarterly Report of the Rail Technical Research Institute, Japan, March, pp. 35-41.
Bastin R (2005) Development of German non-ballasted track forms. Proceedings of the Institution of Civil Engineers Transport 159: 25-39.

Blight GE (1997) Interactions between the atmosphere and the Earth. Géotechnique 47(4): 715-767.

Briggs KM, Smethurst JA, Powrie W and O'Brien AS (2013) Wet winter pore pressures in railway embankments. Proceedings of the Institution of Civil Engineers - Geotechnical Engineering 166(5): 451-465.

Cardoso R, Alonso EE and Neves EMD (2013) A constitutive model for compacted expansive and bonded marls. Géotechnique 63(13): 1116-1130.

Cary CE and Zapata CE (2010) Enhancement of the model for resilient response of soils due to seasonal environmental changes implemented in the M-EPDG. Transportation Research Record 2170: 36-44.

CEN (Comité Européen de Normalisation) (2005) EN 14363:2005: Railway applications - testing for the acceptance of running characteristics of railway vehicles - testing of running behaviour and stationary tests. CEN, Brussels, Belgium.

CEN (2008) EN 13848-5:2008: Railway applications - track track alignment design parameters - track gauges $1435 \mathrm{~mm}$ and wider - part 1: plain line. CEN, Brussels, Belgium.

CEN (2010) EN 13803-5:2010: Railway applications - track track geometry quality - part 5: geometric quality levels plain line. CEN, Brussels, Belgium.

CHSRA (California High Speed Rail Authority) (2012) Geotechnical. California High-Speed Train Project Design Criteria. CHSRA, Sacramento, CA, USA.

Dueñas RA (2010) Elementos de Ayuda para la Toma de Decisiones sobre la Utilización de Vias sin Balasto. MSc thesis, Universidad Politécnica de Cataluña, Barcelona, Spain (in Spanish).

Esveld C (2010) Recent developments in high-speed track. First International Conference on Road and Rail Infrastructure, Opatija, Croatia.

Ferreira TM and Teixeira PF (2012) Rail track performance with different subballast solutions: traffic and environmental effects on subgrade service life. Journal of Transportation Engineering 138(12): 1541-1550. 
Ferreira TM, Teixeira PF and Cardoso R (2011) Impact of bituminous subballast on railroad track deformation considering atmospheric actions. Journal of Geotechnical and Geoenvironmental Engineering 137(3): 288-292.

Gens A (2010) Soil-environment interactions in geotechnical engineering. Géotechnique 60(1): 3-74.

Gens A and Alonso EE (1992) A framework for the behaviour of unsaturated expansive clays. Canadian Geotechnical Journal

Q42 29: 1013-1032.

Gens A, Vaunat J, Garitte B and Wileveau Y (2007) In situ behaviour of a stiff layered clay subject to thermal loading: observations and interpretation. Géotechnique 57(2): 207-228.

Gitirana Jr G and Fredlund EDG (2005) From experimental evidence towards the assessment of weather-related railway embankment hazards. In Unsaturated Soils: Experimental Studies

Q43 (Schanz T(ed.)). Springer. Berlin, Germany, pp. 435-467. Indraratna B, Salim W and Rujikiatkamjorn C (2011) Advanced Rail Geotechnology-ballasted Track. CRC, Boca Raton, FL, USA.

Köppen W (1936) Handbuch der Klimatologie: Das

Q44 geographische System der Klimate, vol. 1, part C (in German). Louis JF (1979) A parametric model of vertical eddy fluxes in the atmosphere. Boundary-Layer Meteorology 17(2): 187-202.

McKeen RG (1985) Validation of Procedures for Pavement Design on Expansive Soils. New Mexico Engineering Research

Q45 Institute, NM, USA, Final Report AD-A160739.

Melis M (2006) Terraplenes y Balasto en Alta Velocidad Ferroviaria

Q46 [primera parte]. Revista de Obras Públicas, pp. 7-16 (in Spanish). NCHRP (National Cooperative Highway Research Program) (2004) Guide for Mechanistic-Empirical Design of New and Rehabilitated Pavement Structures. Transportation Research Board, Washington, DC, USA.

Oldecop LA and Alonso EE (2007) Theoretical investigation of the time-dependent behaviour of rockfill. Géotechnique 57(3): 289-301.

Olivella S, Gens A and Alonso EE (1996) Numerical formulation for a simulator (CODE_BRIGHT) for the coupled analysis of saline media. Engineering with Computers 13(7): 87-112.

Oteo CS, Salinas JL, Ayala FJ and Ferrer M (1995) Risk map for swelling of soils in Spain: results. In Proceedings of the 1st

Q47 International Conference on Unsaturated Soils, Paris, France, vol. 34, pp. 915-920.

Porr Bau GmbH (2012) Slab track Austria - System Öbb-Porr Elastically Supported Slab. Porr Bau GmbH, Austria. See $\mathrm{http}: / /$ www.porr-group.com/fileadmin/content/03_Leistungen/ 03_Infrastruktur/04_Bahnbau/Prospekt_OEBB-Porr_FF-

Q48 System_en.pdf (accessed__/07/2015).

Qadad AA, Shahrour I and Rouainia M (2012) Influence of the soil-atmosphere exchange on the hydric profile induced in soil-structure system. Natural Hazards and Earth System Science 12(6): 2039-2049.

Ridley AM and Pérez-Romero J (1998) Suction-water content relationships for a range of compacted soils. 2nd International

Q49 Conference on Unsaturated Soils, Beijing, China.

Rouainia M, Davies O, O'Brien T and Glendinning S (2009) Numerical modelling of climate effects on slope stability.
Proceedings of the Institution of Civil Engineers Engineering Sustainability 162(2): 81-89.

Samat S (2015) Thermo-hydro-mechanical Modelling of Ground Response under Climatic Actions. PhD thesis, Universitat Politècnica de Catalunya, Barcelona, Spain.

Sánchez M, Wang D, Briaud JL and Douglas C (2014) Typical geomechanical problems associated with railroads on shrinkswell soils. Transportation Geotechnics 1(4): 257-274.

Smethurst JA, Briggs KM, Powrie W, Ridley A and Butcher DJE (2015) Mechanical and hydrological impacts of tree removal on a clay fill railway embankment. Géotechnique, http://dx. doi.org/10.1680/geot.14.P.010.

Sun L, Chen L and Zelelew HH (2013) Stress and deflection parametric study of high-speed railway CRTS-II ballastless track slab on elevated bridge foundations. Journal of Transportation Engineering 139(12): 1224-1234.

Tseng KH and Lytton RL (1989) Prediction of permanent deformation in flexible pavement materials. In Implication of Aggregates in the Design, Construction, and Performance of Flexible Pavements (Schreuders HG and Marek CR (eds)). ASTM, Philadelphia, PA, USA, pp. 154-172.

UIC (Union Internationale des Chemins de fer) (2008) Earthworks and Track Bed for Railway Lines: UIC Leaflet 719 $R$, 3rd edn. UIC, Paris, France.

Van Genuchten MT (1980) A closed-form equation for predicting the hydraulic conductivity of unsaturated soils. Soil Science American Journal 44: 892-898.

Vardon PJ, Bashir R and Sharma J (2015) Discussion: Climatic influence on geotechnical infrastructure: a review. Environmental Geotechnics 4: 249-252, http://dx.doi.org/10. 1680/envgeo.14.00049.

Vaunat J (2013) Soil-atmosphere interactions. Lecture Notes, Code_Bright Short Course 2013.

Vaunat J and Gens A (2005) Analysis of the hydration of a bentonite seal in a deep radioactive waste repository. Engineering Geology 81(3): 317-328.

Villarraga C, Ruiz D, Vaunat J and Casini F (2014) Modelling landslides induced by rainfall: a coupled approach. Procedia Earth and Planetary Science 9: 222-228.

Vossloh (2010) Rail Fastening Systems for Slab Tracks: System 300. Vossloh. See http://www.vossloh-fastening-systems.com/ en/produkte_2010/feste_fahrbahn/300/300.html (accessed /07/2015).

Zapata CE, Andrei D, Witczak MW and Houston WN (2007) Incorporation of environmental effects in pavement design. Road Materials and Pavement Design 8(4): 667-693.

\section{WHAT DO YOU THINK?}

To discuss this paper, please submit up to 500 words to the editor at journals@ice.org.uk. Your contribution will be forwarded to the author(s) for a reply and, if considered appropriate by the editorial panel, will be published as a discussion in a future issue of the journal.

1 


\section{Author Queries}

Q1: Please verify that the authors' affiliations are correct.

Q2: Please check: variables $\boldsymbol{g}$ and $\boldsymbol{I}$ are not used in the text.

Q3: Please check. The same variable $P$ is used for three quantities.

Q4: Two definitions were originally provided for $P_{1}$. Please check the retained definition.

Q5: Two definitions were originally provided for $R_{\mathrm{n}}$. Please verify that the definition retained is correct.

Q6: Please check if " $S_{1}$ " and " $S_{1,0}$ " are the same as " $S_{\mathrm{r}}$ and " $S_{\mathrm{r}, 0}$ " (see Equation 8). Please note that in Table 2, both subscripts $r$ and I are used.

Q7: Please verify change of "Sun et al., 2011" to "Sun et al., 2013".

Q8: Please verify the definition of Aashto.

Q9: Please check change of "TH" to "T-H".

Q10: Please define $a_{1}$ and $a_{2}$ and include their definitions in the Notation list.

Q11: Abbreviations/acronyms that can be pronounced as a word should have initial caps only (unless a source which presents them in all caps is being quoted directly).

Q12: Please check if " $S_{1}$ " and " $S_{1,0}$ " are the same as " $S_{\mathrm{r}}$ and " $S_{\mathrm{r}, 0}$ " (see Notation list). Please note that in Table 2 , both subscripts $\mathrm{r}$ and I are used.

Q13: Please check if "Sánchez et al., 2015” should be "Sánchez et al., 2014”. If not, please add Sánchez et al. (2015) to the list of references.

Q14: Please check change of ". I" to " $\times 1$ " in the $K$ values in Table 2.

Q15: Please provide definitions of $\lambda_{\text {dry }}$ and $\lambda_{\text {sat }}$ in the Notation list.

Q16: Please verify that changes in "where $\beta_{\mathrm{g}}$ is an aerodynamic ... are measured" have preserved your meaning.

Q17: Please define $2 \mathrm{H} / 1 \mathrm{~V}$ if possible.

Q18: Please provide definitions of the ff. in the Notation list: $\gamma_{\text {dry }}, \gamma_{\text {sat }}, E^{\prime}, v, \phi^{\prime}, c^{\prime}$, and $w_{\text {opt }}$.

Q19: Please replace "CBR" with a single-character variable with subscripts and provide its definition in the Notation list.

Q20: Please define $L_{\mathrm{L}}$ and $I_{\mathrm{P}}$ and include their definitions in the notation list.

Q21: Please note that unless you have paid for colour printing, we cannot include references to colour in figure captions. Please amend Figure 3 and its caption as necessary.

Q22: Please define $I_{\mathrm{h}}$ and include the definition in the Notation list.

Q23: Case numbers have been presented consistently as "UMA" followed by a number without a hyphen. Please check.

Q24: Please check the sentence "In the absence membranes ... at a given location" for missing text.

Q25: Please verify that changes in the sentence "In the drier climate ..." have preserved your meaning.

Q26: Please define $z$ and include the definition in the Notation list.

Q27: Please check changes in Figure 7 caption.

Q28: For EN 13803-5:2010, EN 14363:2005, and EN 13848-5:2008, please specify the country-specific standards referred to.

Q29: Please include DB (1999) in the list of references.

Q30: Please check if "apud" should be "and".

Q31: For EN 13803-1:2010 and EN 14363:2005, please specify the country-specific standards referred to.

Q32: Please verify definitions of Cemosa and Feder.

Q33: Please define CDTI.

Q34: Please provide DOIs for all journal and proceedings references where available.

Q35: Please verify definition of Adif.

Q36: Please provide issue no. for Bastin R (2005).

Q37: For EN 13803-5:2010, EN 14363:2005, and EN 13848-5:2008, please specify the country-specific standards referred to.

Q38: Please verify definition of CHSRA.

Q39: Please provide page nos. for CHSRA (2012).

Q40: Please verify that Dueñas RA (2010) is an MSc thesis.

Q41: Please provide page nos. for Esveld C (2010).

Q42: Please provide issue no. for Gens A and Alonso EE (1992).

Q43: Please verify editor for Gitirana JrG and Fredlund EDG.

Q44: Please provide publisher name and location details for Köppen W (1936).

Q45: Please provide city/town location of New Mexico Engineering Research Institute.

Q46: Please provide month or date for Melis M (2006).

Q47: Please provide list of editors for Oteo et al. (1995). 
Q48: For Porr Bau GmbH (2012), please provide city/town location of Porr Bau GmbH and the day of the accessed date. Q49: Please provide page nos. for Ridley AM and Pérez-Romero J (1998).

Q50: Please verify that Samat $\mathrm{S}(2015)$ is a $\mathrm{PhD}$ thesis.

Q51: Please provide volume, issue, and page nos. for Smethurst et al. (2015).

Q52: Please verify editors for Tseng KH and Lytton RL (1989).

Q53: Please verify definition of UIC.

Q54: Please provide issue no. for Van Genuchten MT (1980).

Q55: Please provide issue no. for Vardon et al. (2015).

Q56: If Vaunat J (2013) is published material, please provide editors' names, publisher's name and location details, and page nos. If not published, please delete it from the list of references and mention it in the text only.

Q57: Please provide issue no. for Villarraga et al. (2014).

Q58: Please provide location details for Vossloh and day of accessed date. 